\title{
Meckel Divertikülü'nün Nadir Rastlanan Komplikasyonu: Illeus ve Divertikülit Birlikteliği
}

\author{
A Rare Complication of Meckel's Diverticulum: Coexistence of Ileus and Diverticulitis \\ Mehmet Fatih HASKARACA ${ }^{1}$, Mustafa OZSOY ${ }^{2}$, Ahmet BAL ${ }^{2}$, \\ Ziya Taner OZKECECi², Serdar KOKULU³ ${ }^{3}$, Sezgin YILMAZ², Yüksel ARIKAN² \\ ${ }^{1}$ Manisa Merkezefendi Devlet Hastanesi, Genel Cerrahi Kliniği, Manisa \\ ${ }^{2}$ Afyon Kocatepe Üniversitesi Tıp Fakültesi, Genel Cerrahi Kliniği, Afyonkarahisar \\ ${ }^{3}$ Afyon Kocatepe Üniversitesi Tıp Fakültesi, Anestezi ve Reanimasyon Kliniği, Afyonkarahisar
}

\section{ÖZET}

Gastrointestinal sistemin en sık rastlanan konjenital anomalisi Meckel divertikülüdür. Çoğunlukla asemptomatiktir. Genellikle komplikasyonların geliştiği durumlarda tanı alırlar. Klinik yaşa bağı değişiklik göstermektedir. Erişkin yaş grubunda en sık rastlanan komplikasyon obstrüksiyon tablosu iken ikinci sırayı divertikülit almaktadır. Bu makale ile obstrüksiyon ve dıvertikülit tablosunu es seanslı barındıran bir olguyu literatür bilgileri ışığında sunmayı amaçladık.

Anahtar Kelimeler: Meckel Divertikülü; obstrüksiyon; komplikasyon.

\section{Giriş}

Meckel divertikülü (MD) \%2'lik bir oran ile gastrointestinal sistemin en sık görülen konjenital anomalisidir. Tüm barsak katmanlarını içeren MD barsağın komplet yani gerçek divertiküllerindendir. Divertikül boyutlarının 1-2 cm'den $20 \mathrm{~cm}$ 'e kadar uzunlukta olabildiği bildirilmiştir. Genellikle asemptomatik olmakla birlikte kanama, perforasyon, obstrüksiyon gibi hayati tehdit edebilen komplikasyonlara neden olabilmektedir (1). MD olan

Yazışma Adresi / Correspondence: Yrd. Doç. Dr. Mustafa Özsoy Afyon Kocatepe Üniversitesi, 2. Kat Genel Cerrahi Kliniği

E-Mail: dr.mustafaozsoy@gmail.com

\begin{abstract}
Meckel diverticulum is the most common congenital anomaly in the gastrointestinal tractus. Meckel diverticulum is mainly asymptomatic. They mostly couldn't be diagnosed until the complications appear. Clinical picture varies according to age. Intestinal obstruction is the most common complication, found in adult group and also second one is diverticulitis. Here in, we reported and discussed a case with mechanical obstruction and diverticulitis found at the same time in the view of the current literature.
\end{abstract}

Keywords: Meckel Diverticulum; obstruction; complication.

hastaların sadece $\% 5$ 'i hayat boyunca semptomatik hale gelirler. Semptomatik olan hastaların da \%6'sı komplikasyonlar nedeniyle hayatlarını kaybederler (2). Bu makalede $\mathrm{MD}^{\prime}$ ün en sık rastlanan iki komplikasyonu olan divertikülit ve obstrüksiyon tablosunu aynı anda barındıran bir olguyu sunmaktayız.

\section{OLGU SUNUMU}

19 yaşında bayan hasta, karın ağrısı, bulantı ve kusma şikâyeti ile başvurdu. Öz ve soy geçmişinde özelliğe rastlanmadı. Fizik muayenesinde tüm karın kadranlarında olmak üzere özellikle sağ alt kadranda periton hassasiyet tablosu hâkimdi. Laboratuar incelemelerinde $15,500 / \mathrm{mm}^{3}$ lökositozun dışında diğer değerleri olağan sınırlar içerisinde idi. Ayakta 
direkt karın grafiğinde ince barsak kökenli yaygın hava SIVI seviyelenmeleri saptanan hastanın batın ultrasonografisinde karın sağ alt kadranında genişlemiş barsak ansları ve periçekal sıvı saptanmadı. Hasta mevcut anamnez, fizik muayene, laboratuar verileri ve görüntüleme yöntemleri doğrultusunda akut perfore apandisit ön tanısı ile operasyona alındı. Paramedian insizyon ile karına girildi. Karın içi gözleminde yaygın seröz nitelikte reaksiyonel mayi mevcuttu. Apendiksin olağan saptanması üzerine eksplorasyona devam edildi. ileoçekal mesafeden yaklaşık $60 \mathrm{~cm}$ proksimalde meckel divertiküliti ve divertikülün mezosunda yaklaşık $3 \mathrm{~cm}$ çapında açıklık gözlendi (Şekil 1). Bu açıklıktan jejunal ince barsak anslarının girdiği ve mekanik obstrüksiyon tablosuna yol açtğı saptandı (Şekil 2). Ince barsak ansları açıklıktan kurtarıldı. İskemik tabloya rastlanmadı. Divertikülit için parsiyel ince barsak rezeksiyonu uygulandı. Hastada majör cerrahi sorunla karşılaşılmadan postoperatif 7. Gün şifa ile taburcu edildi.

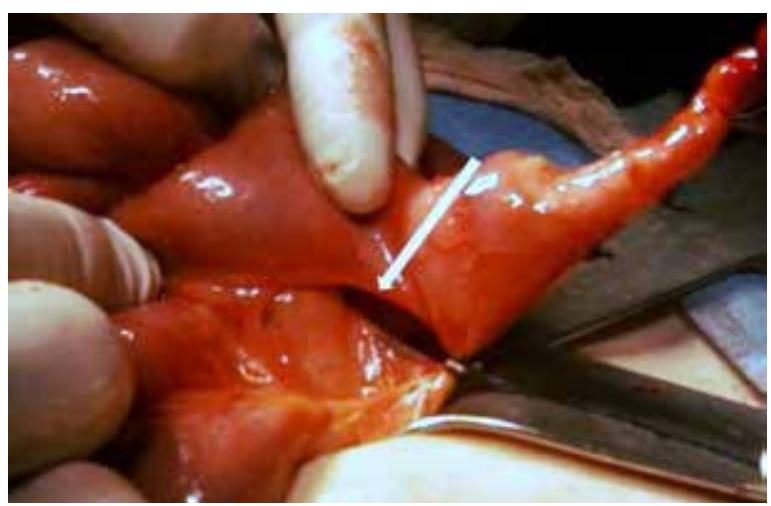

Şekil 1: Meckel divertiküliti ve divertikülün mezosunda yaklaşık $3 \mathrm{~cm}$ çapında açıklık görülmektedir (Beyaz Ok).

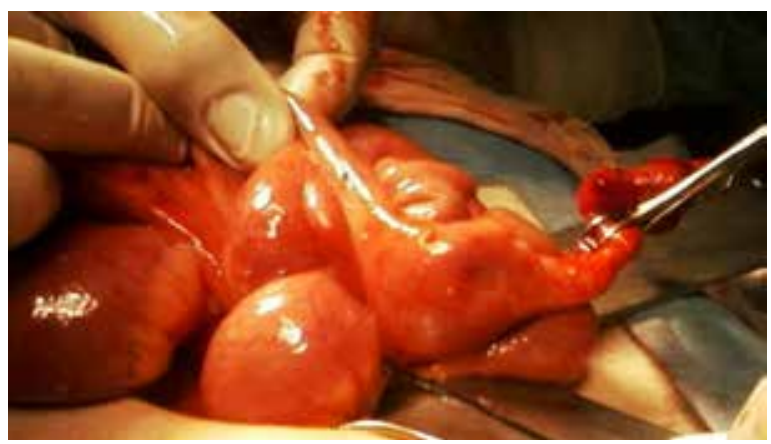

Şekil 2: Mezodaki fenestrasyondan ince barsak ansları girerek mekanik barsak obstrüksiyon tablosu oluşturmuştur.

\section{TARTIŞMA}

MD ilk kez alman anatomist J. Friedrich Meckel'den tarafindan tanımlanmıştır (1). Illeumun son kısmında antimezenterik yüze yerleşen MD, embriyolojik gelişimin 5-8 haftasında omfolomezenterik kanalın kapanmaması nedeniyle ortaya çıkarmaktadır (2). MD' ne özgü bir klinik tablo bulunmamaktadır. Hastaların büyük çoğunluğu asemptomatiktir ve genellikle komplikasyonların geliştiği durumlarda tanı alırlar (3). MD' ne ait komplikasyonların başlıcaları divertikülit, gastrointestinal kanama, barsak tıkanıklığı, perforasyon ve invajinasyondur. Ameliyat öncesi komplikasyon gelişmemiş MD olgularında tanının konması oldukça güçtür ve komplikasyonların geliştiği taktirde şayet zamanında tedaviye başlanmazsa yaşamı tehdit eden sonuçlar karşımıza çıkabilmektedir (4). MD bulunan hastaların yaklaşık \%5'i hayatların bir döneminde komplikasyon gelişmektedir (5). Erişkin dönemde en sık rastlanan MD komplikasyonu obstrüksiyondur. Obstrüksiyon nedenleri arasında ileum ve batın duvarı arasında uzanan omfolomezenterik fibrotik bantın varlığı, çekum volvulusu, invajinasyon, internal fittklaşma gibi mekanizmalar sayılabilmektedir (6). İkinci en sıklıkla karşılaşılan MD komplikasyonu divertikülittir. Genellikle dar boyunlu divertikülün ağzının tıkanması sonucunda gelişir ve sıklıkla akut apandisit ile karışılabilmektedir (7). Tanı akut apandisit ön tanısı ile cerrahiye alınan hastalarda ameliyat esnasında konur. Olgumuzda $\mathrm{MD}^{\prime}$ ün bilinen en sık iki komplikasyonu olan obstrüksiyon ve divertikülit tablosu iç içe geçmiştir. Divertikülit tablosu olgumuzda olduğu gibi akut apandisiti taklit etmiştir. Yazarca kabul gören görüş ise akut apandisit ön tanısıyla operasyona alınan negatif laparatomili olgularda MD' ün mutlaka araştırması gerekliliğidir (8). Olgumuzda ilginç olan nokta aynı anda mekanik barsak obstrüksiyon tablosunun da bulunmasıdır. MD mezosundaki açıklıktan ince barsakların girerek, mekanik obstrüksiyon tablosu oluşturulması nadir rastlanan bir durumdur. Mezenterleri ile birlikte barsakların visseral peritondaki açıklıktan içerilere girmesine internal herniasyon adı verilmektedir. Olgumuzda bu gruba dâhildir. Oldukça nadir rastlanan bu herni tipi mekanik barsak obstrüksiyonu yapan nedenlerin arasında \%1'in altında bir insidansa sahiptir. Internal herniler edinsel veya konjenital 
olabilir (9). Olgu daha önce geçirilmiş herhangi bir travma ve cerrahi öyküsü bulunmadığından mezodaki açıklığın konjenital olduğu aşikardır. Cerrahi tedavi prosedürleri çeşitlilik gösterse, en uygun cerrahi tedavi prosedürü divertikülü içine alacak şekilde segmenter ince barsak rezeksiyonudur. Karşılaşılan morbidite ve mortalite oranları komplikasyonların ciddiyetine ve hastanın içinde bulunduğu kondisyonel durumu ile yakın ilgilidir. Bazı serilerde mortalite oranlarının \%5’lere kadar çıktı̆ı gözlenmiştir (10).

\section{SONUÇ}

Meckel divertikülü gastrointestinal sistemin en sık rastlanan konjenital anomalisidir. Erişkin yaş grubunda en sık saptanan meckel divertikül komplikasyonları obstrüksiyon ve divertikülittir ve hastalar birden fazla komplikasyonu aynı zamanda barındırabileceği akılda tutulmalıdır.

\section{KAYNAKLAR}

1. Bani-Hani KE, Shatnawi NJ. Meckel's diverticulum: comparison of incidental and symptomatic cases. World J Surg 2004;28(9):917-20.

2. Williams RS. Management of meckel's diverticulum. Br J Surg 1981;68(7):477-80.
3. Akcakaya A, Alimoğlu O, Ozkan OV, Sahin M. Complicated Meckel's diverticulum. Ulus Travma Acil Cerrahi Dergisi 2003;9(4):246-9.

4. Cullen JJ, Kelly KA. Current management of Meckel's diverticulum. Adv Surg 1996;29(1):207-14.

5. Soltero MJ, Bill AH. The natural history of Meckel's Diverticulum and its relation to incidental removal. A study of 202 cases of diseased Meckel's Diverticulum found in King County, Washington, over a fifteen year period. Am J Surg 1976;132(2):168-73

6. Aldemir M, Yılmaz G, Girgin S. Meckel divertikulune bağlı ince barsak torsiyonu. Kolon Rektum Hastalıkları Dergisi 2000;10(3): 94-5.

7. Turgeon DK, Barnett JL. Meckel's Diverticulum. Am J Gastroenterol 1990;85(7):777-81.

8. Korkmaz O, Yılmaz HG, Keleş C. Erişkinlerde görülen Meckel divertikül komplikasyonları. Dicle Tıp Dergisi 2008;35(2):91-5.

9. Pinero $A$, Martinez-Barba $E$, Canteras $M$, Rodriquez JM, Castellanos G, Parrilla P. Surgical management and complications of Meckel's diverticulum in 90 patients. Eur J Surg 2002;168(1):8-12.

10. Root GT, Baker CP. Complications associated with Meckel's diverticulum. Am J Surg 1967;114(2):285-8. 
